\title{
Assessing the energy justice implications of bioenergy development in Nepal
}

\author{
Caroline Damgaard, Darren McCauley ${ }^{*}$ and Jed Long
}

\begin{abstract}
Background: The emerging concept of energy justice has focused on the justice implications of conventional energy systems (oil, gas, coal, etc.). Instead, we focus on the meaning of energy justice in the context of unconventional energy systems, by investigating small-scale bioenergy development in Nepal. We approach energy justice as a conceptual framework that focuses on social justice implications of energy systems, with an emphasis on burden/benefit distributions and procedural or post-distributive justice, and consider its applicability beyond conventional energy systems.

Methods: Research was carried out in two parallel phases: (1) a quantitative phase, based on spatial analysis of secondary data, explores bioenergy distribution in Nepal, in relation to social-demographic characteristics, to investigate processes of distributive justice, and (2) a qualitative phase, based on thematic analysis of primary interview data, looks at post-distributive aspects of the energy reality in Nepal, to critically discuss the meaning of energy justice in this context.

Results: 1) Biogas development is unevenly distributed, following patterns of social connectedness, which suggests significant spatial variation in capabilities or capability deprivations regarding individual agency in relation to (bio)energy.

2) There is a surprising inconsistency in the relationship between socially marginalised populations and attainment of biogas across the country, which needs further research.

3) Individual agency, supported or facilitated by enabling actors-particularly local biogas companies—is a key characteristic of local biogas development.

4) Decentralised, small-scale energy development gives rise to power dynamics differing fundamentally from those of conventional centralised energy systems, through radically different processes of procedural justice.

Conclusions: Processes of energy justice are shown to exhibit strong spatial variability and are associated with social connectedness. Analysis focusing on processes of agency and empowerment leads to the conclusion that energy justice, to encourage unconventional energy development, should emphasise the necessary interconnection of individual rights, empowerment and responsibility.
\end{abstract}

Keywords: Energy justice, Unconventional energy, Distributive justice, Post-distributive justice, Nepal, Bioenergy

\footnotetext{
* Correspondence: dam7@st-andrews.ac.uk

Department of Geography \& Sustainable Development, University of St

Andrews, Irvine Building, North Street, St Andrews KY16 9AL, Fife, Scotland, UK
} 


\section{Background}

Globally, over 1.3 billion people lack access to electricity, and a further 2.6 billion people rely on the use of biomass for cooking, with proven adverse health impacts [1]. This lack of appropriate energy sources is disproportionately concentrated in poor, rural areas in developing countries [1, 2], causing concerns of energy equity, both internationally and nationally, and making energy access a primary concern for policy makers and development agencies [3]. This has motivated significant interest in small-scale renewable energy solutions as alternatives to 'conventional energy systems' around the world. This trend is also increasingly apparent in 'developed' country contexts; in Europe, for example, evidence is mounting of local authorities, organisations and community groups taking control of their own energy services, in order to ensure a more sustainable local development path than set out by national energy policies [4]. While energy justice as a research agenda has primarily concerned justice issues of large-scale energy development, this increasing attention to small-scale, decentralised energy solutions, across the world, warrants an exploration of the concept in 'unconventional' energy contexts. Our contribution to energy justice literature thus involves a systematic focus upon unconventional, rather than conventional, energy systems.

Through a case study of small-scale bioenergy development in Nepal, we aim to show how energy justice may be applied to small-scale, decentralised energy systems, and draw insights from our findings to further develop the concept. To this end, we first highlight how its roots in capability-centred justice theory make energy justice well-placed for addressing energy debates in terms of individuals' ability to influence their own energy realities. We then present our methodology, comprising of both quantitative spatial analysis and qualitative research, followed by results and a discussion hereof.

\section{Energy justice and the capability approach}

We acknowledge the foundational 'tenets' approach to energy justice as introduced by McCauley et al. [5, 6], originating from environmental justice literature (notably Schlosberg [7]) as well as the climate justice and fuel poverty-inspired approach of Bickerstaff et al. [8]. A detailed account of these and other related developments in energy justice literature can be found in Jenkins et al. [9]. Energy justice is widely understood in terms of the three tenets: distributive, procedural and recognition justice [5]. In addition, the contemporary work of Benjamin Sovacool provides a useful reference point for this exploration of unconventional energy systems.

Sovacool et al. [10] place the energy justice concept firmly within the capability approach to justice, as associated with
Amartya Sen and Martha Nussbaum. The concept of capability-centred justice is introduced by Sen [11], who defines capability as 'a person's freedom to pursue functionings that he/she has reason to value' ([12], p. 4-5), where functionings are what constitute a person's being-with both a well-being and an agency aspect ([12], p. 59-62). Notably, Sen [13] also highlights the burdens/responsibilities associated with personal freedom and thus extends the concept of capability beyond a purely rights-based discourse of justice, a point pursued in the discussion (the 'Discussion' section).

In addition to 'freedom', equality is a fundamental constituent of justice. Sen [12] argues that the fundamental question, which any theory of justice must address, is: 'equality of what?'. While a Rawlsian perspective would focus on equality of access to primary goods, the capability approach insists, rather, on equality of capabilities or opportunities to function. In the context of energy justice, a concern with equality of capabilities transcends questions of access to energy as a 'good' or a service, to include also a focus on individuals' freedoms and functioning in terms of agency. These ideas are evident in Sovacool et al.'s [10] four underlying assumptions (Table 1) of energy justice. These lead to the identification of two foundational principles of energy justice: an affirmative and prohibitive principle. The latter focuses on negative externalities of the energy sector, while the former emphasises individuals' positive right to basic energy services and is concerned with the concepts of 'energy poverty' and distributive conceptualisations of justice.

Energy justice in the context of conventional systems tends to focus on the prohibitive principle (though with increasing concerns also of energy poverty [14]), whereas work relating to developing countries relates more closely to the affirmative principle but typically using language of equality rather than justice, specifically [15] (reflected upon further in the discussion). Energy is recognised as a prerequisite for most basic capabilities, to which people are entitled (assumption 4), bringing energy development into the arena of social and international development. The capability approach offers a justice-related perspective also on development; Sen ([13], p. 3) defines

Table 1 Assumptions of energy justice

\begin{tabular}{|c|c|}
\hline Assumption 1 & $\begin{array}{l}\text { "Every human being is entitled to the minimum } \\
\text { of basic goods of life that is still consistent with } \\
\text { respect for human dignity." }\end{array}$ \\
\hline Assumption 2 & $\begin{array}{l}\text { Basic goods "include the opportunity to develop } \\
\text { the characteristically human capacities needed } \\
\text { for a flourishing human life" }\end{array}$ \\
\hline Assumption 3 & $\begin{array}{l}\text { "Energy is only an instrumental good - it is not } \\
\text { an end in itself" }\end{array}$ \\
\hline Assumption 4 & $\begin{array}{l}\text { "Energy is a material prerequisite for many of } \\
\text { the basic goods to which people are entitled." }\end{array}$ \\
\hline
\end{tabular}

Source: Adapted from Sovacool et al. [10] 
development as 'a process of expanding the real freedoms that people enjoy' and conceptualises poverty as 'capability deprivation' and freedom as both constitutive of and instrumental to 'development'. Thus, 'unfreedoms' are seen as the source of poverty and underdevelopment, as well as a barrier to development. These unfreedoms may be process driven (relating to procedural justice) or may concern opportunity access (an individual's real opportunity to achieve a valued end). It follows from the distinction between these different forms of unfreedoms-when applied to the energy context-that energy justice, correspondingly, operates at different levels (Table 2), a point further pursued in the discussion.

\section{Unfreedoms of energy systems}

Arguably, the process aspect of unfreedoms [13] is characteristic of conventional energy systems, where users are entirely removed from energy production and distribution [4, 16, 17]. When Sovacool et al. [10] write that energy empowers us as individuals but renders us powerless as citizens, they express a key concern with conventional energy systems, similar to Mumford's [18] critical discussion about 'authoritarian and democratic technics'. The basic argument is that conventional energy systems have become so large, centralised and technology dependent, that we as humans/individuals have lost control, and that energy is no longer just instrumental for human activities, but dictating them. These ideas are significant in relation to this research, investigating whether/how small-scale, off-grid renewable energy development may be potentially a more 'democratic technology' and how it relates to energy justice.

Similar ideas are evident in much contemporary academic literature. Environmental justice scholars have criticised the 'disconnected geographies of responsibility and outcome' [17], and in energy justice literature, many have pointed to a geographical and psychological distance between energy production and consumption in centralised systems and a disconnect between consumers and the energy they use $[4,16,19]$. Miller et al. [20] conclude that 'alternative energy futures' could be more just and less ecologically destructive than conventional

Table 2 Sen's unfreedoms

\begin{tabular}{lll}
\hline & Procedural unfreedom & $\begin{array}{l}\text { Unfreedom in } \\
\text { opportunities }\end{array}$ \\
\hline $\begin{array}{lll}\text { In the energy } \\
\text { context }\end{array}$ & $\begin{array}{l}\text { Unfreedom of } \\
\text { choice and } \\
\text { participation in } \\
\text { energy matters }\end{array}$ & $\begin{array}{l}\text { Inadequate access to } \\
\text { functionings relying } \\
\text { on energy/inadequate } \\
\text { access to 'society' }\end{array}$ \\
Type of injustice & $\begin{array}{l}\text { Agency capability } \\
\text { deprivation }\end{array}$ & $\begin{array}{l}\text { Well-being capability } \\
\text { deprivation (and potentially } \\
\text { agency deprivation) }\end{array}$ \\
Characteristic of & Authoritarian technics &
\end{tabular}

Source: Adapted from Sen [13] systems and could increase democratic participation in technological matters. Also in more technical literature, preference for off-grid, decentralised energy development can be found, as considered more independent and autonomous than large-scale grid structures [21].

\section{Methods}

Based on two underlying research questions, we seek to address distributive and 'post-distributive' ${ }^{\text {' }}$ aspects of justice, respectively, in Nepal's bioenergy context:

1. How does the geographical distribution of smallscale bioenergy plants in Nepal relate to the physical and social landscapes?

2. How does bioenergy development/practice 'on the ground' relate to post-distributive aspects of justice, in Nepal?

\section{Research design}

A mixed methods approach was formulated for the study, in order to examine different aspects of energy justice, which lend themselves to different types of scientific enquiry. Quantitative spatial methods are highly suitable to address questions of distributional justice, while qualitative methods are more appropriate to investigate postdistributive aspects of justice. Furthermore, this approach was intended to facilitate a comprehensive investigation based on both quantitative spatial analysis of the bioenergy and socio-economic landscapes and qualitative inquiry grounding the analysis in its real-world context, in line with a contemporary call for greater incorporation of qualitative methods in energy studies [22].

\section{Case selection: Nepal and biogas}

Nepal is one of the world's poorest nations [23], with around $60 \%$ of the population lacking access to clean and reliable energy $[24,25]$, and the vast majority $(87 \%)$ of energy consumption covered by traditional energy sources (firewood, cowdung, etc.; [26, 27]. Load-shedding is a common occurrence in Nepal, where electricity provision through the national grid is reliable often for less than $8 \mathrm{~h}$ in a day [28]. With over $75 \%$ of the population living in rural areas, rural energy development is a pressing concern in Nepal.

Only $1.5 \%$ of the economically and technically viable renewable energy potential is currently being exploited in Nepal [23], leaving significant potential for further development of renewable energy in Nepal. Small-scale biogas is one renewable energy technology promoted as part of the government's rural energy development efforts. Biogas is a methane-rich gas produced through the breakdown of organic matter in a process of anaerobic digestion. In Nepal, biogas is primarily intended to provide clean energy for cooking-with limited potential to 
be used also for lighting-as an alternative to traditional energy sources. Domestic biogas digesters of $2-8 \mathrm{~m}^{2}$ in size are the most common in Nepal, as well as larger community digesters for connection of multiple households. Users feed agricultural waste (especially cow dung) and potentially household waste (toilet and kitchen waste) into the digester, together with water. Anaerobic digestion then produces gas-which typically leads through a pipe connected to a clean cooking stove-and a slurry by-product, which is rich in nutrients and can be used as fertiliser.

Important considerations in relation to bioenergy in Nepal include the varied topology and physical environment; biogas production is dependent on temperature, water and biomass availability, which vary significantly across Nepal. Furthermore, biomass availability is dependent on presence of cattle, and generally, biogas is considered most suitable for households/communities engaging in agricultural activity, to fully exploit the benefits of biogas, by the use of the slurry by-product as fertiliser. Furthermore, biogas feasibility is linked to site accessibility - a major issue in Nepal, where $75 \%$ of the population live in remote areas.

Culturally, Nepal faces a unique challenge in relation to equality between castes and ethnic groups. While not formally enforced, the complex traditional caste system is still associated with socio-economic disadvantages for marginalised castes and ethnic groups [29], something which national development programmes address through, for example, targeted subsidies.

Another equality/recognition-related issue, which biogas development aims to address, is the disadvantaged position of women and children in relation to energy consumption [30, 31]. Health problems due to poor indoor climate from burning of traditional fuels impact women and children disproportionately, due to gender roles and division of household chores [23]. The direct benefits of biogas offer potential to improve conditions particularly for women and children.

\section{Quantitative phase}

While distributive energy justice as applied to conventional energy contexts focuses primarily on burden/ benefit distributions, our study presents an alternative conceptualisation, in line with capability-centred justice (the 'Energy justice and the capability approach' section), of distributive justice in a small-scale decentralised energy context. In our quantitative phase, we thus focus on distributive processes relating to ability to access bioenergy technology across Nepal.

Data on the biogas situation in Nepal is compared to variables representing social and physical connectedness, climatic conditions and social marginalisation. Base maps were obtained from the database of Global Administrative Areas (GADM) and the International Centre for Integrated Mountain Development (ICIMOD); other data sources are indicated in Table 3. All quantitative analysis was performed on data aggregated to the administrative unit of the Village Development Committee (VDC) $(n=4050)$. The percentage of households using biogas (\% biogas) was used as the dependent variable in all analysis and represents the penetration of biogas at the household level for each VDC. The percentage of households with a domestic biogas digester ranged from 0 to 52.6, but with the majority $(75 \%)$ of VDCs

Table 3 Variables

\begin{tabular}{|c|c|c|c|}
\hline Variable & & Rationale & Source \\
\hline$\%$ biogas & $\begin{array}{l}\text { BSP registered domestic biogas digesters as } \\
\text { percentage of total number of households in } \\
\text { each VDC }\end{array}$ & Understand biogas distribution & $\begin{array}{l}\text { Biogas Sector } \\
\text { Partnership-Nepal }\end{array}$ \\
\hline Distance & $\begin{array}{l}\text { Distance (via road network) from VDC } \\
\text { centroids to nearest district headquarters }\end{array}$ & $\begin{array}{l}\text { Remote areas are generally disadvantaged, in Nepal, } \\
\text { where inaccessibility is a significant barrier to local } \\
\text { development }\end{array}$ & $\begin{array}{l}\text { Generated based on a } \\
\text { road network dataset } \\
\text { (ICIMOD) }\end{array}$ \\
\hline Elevation & Mean elevation within each VDC & $\begin{array}{l}\text { Biogas efficiency is related to temperature, for which } \\
\text { elevation serves as a useful proxy }\end{array}$ & $\begin{array}{l}\text { CGIAR Consortium for } \\
\text { Spatial Information } \\
\text { (Diva-GIS data service) }\end{array}$ \\
\hline$\%$ female & $\%$ of population made up of women & $\begin{array}{l}\text { Gender inequality is a big concern in Nepal, with } \\
\text { possible implications for the recognition aspect of } \\
\text { energy justice }\end{array}$ & $\begin{array}{l}2011 \text { census } \\
\text { (Central Bureau } \\
\text { of Statistics 2012) }\end{array}$ \\
\hline$\%$ margin & $\begin{array}{l}\% \text { of population categorised as } \\
\text { "marginalised" (categorisation based on } \\
\text { World Bank/DFID (2006) caste/ethnic } \\
\text { groupings) }\end{array}$ & $\begin{array}{l}\text { Social marginalisation by caste and ethnicity is a big } \\
\text { concern in Nepal, with possible implications for the } \\
\text { recognition aspect of energy justice }\end{array}$ & $\begin{array}{l}2011 \text { census } \\
\text { (Central Bureau } \\
\text { of Statistics 2012) }\end{array}$ \\
\hline$\%$ no facility & $\begin{array}{l}\text { \% of households with no household facilities } \\
\text { (radio, TV, telephone, mobile, computer, } \\
\text { Internet and more) }\end{array}$ & $\begin{array}{l}\text { Facility access is used as a proxy for social } \\
\text { connectedness of households, which, just as physical } \\
\text { connectedness, is likely to impact access to (energy) } \\
\text { development }\end{array}$ & $\begin{array}{l}2011 \text { census } \\
\text { (Central Bureau } \\
\text { of Statistics 2012) }\end{array}$ \\
\hline
\end{tabular}


characterised by biogas attainment by less than $2 \%$ of households. Five other variables were derived in order to analyse different factors believed to influence the rate of biogas uptake (Table 3). All analysed variables are shown in the maps in Fig. 1. Average elevation of each VDC is included here as a proxy for temperature [32]; however, elevation is likely associated with a range of processes in Nepal due to the incredible influence of topography in this region. Temperature-dependent efficiency of biogas production suggests that mean annual temperature should, ideally, be at least $20^{\circ} \mathrm{C}$.

When working with spatially autocorrelated variables, OLS regression models may provide biased parameter estimates, which can lead to incorrect inferences [33]. Geographically local models, such as geographically weighted regression, can be utilised to better understand these processes, when the relationships between the independent and dependent variables vary across space. Geographically weighted regression (GWR) [34] allows exploration of spatially varying relationships between variables. In a spatially local regression approach, GWR estimates regression models at each spatial unit, attaching weights to neighbouring observations. Weights are assigned based on a kernel size, which can be either fixed or adaptive. GWR facilitates investigation of spatial variation of regression coefficients, showing how any one variable may relate to the dependent variable differently in different locations; thus, GWR results are typically presented as a map of regression parameters and their significance.

A set of GWR models were evaluated using \% biogas as the dependent variable and all possible combinations of the five independent variables. Each model was evaluated for goodness-of-fit using adjusted $R^{2}$, and comparisons were made between models using the Akaike information criterion (AIC). For the GWR analysis, an adaptive kernel-the $k$ nearest neighbours-was used to account for the heterogeneity of administrative polygons (i.e. VDCs). The optimal number of neighbours $(k)$ for GWR analysis was identified using AIC.

This spatial-statistical analysis is used as a method for examining distributional aspects of energy justice at national scale-in this case study, specifically in relation to development of domestic biogas-and is expected to show differences in biogas attainment co-varying with socio-economic differences across the country. Attention is paid particularly to the caste and gender variables, due to the focus on such inequalities by national policies and development programmes.

\section{Qualitative phase}

To supplement insights from the quantitative phase focusing on national-scale processes of energy justice based on aggregate measures of biogas attainment across the country, a qualitative phase aims to investigate postdistributive aspects of energy justice at the micro-scale. Thus, qualitative interviews with biogas users are conducted to gain an understanding of individuals' lived experiences of small-scale biogas development from an energy justice perspective. Furthermore, the participation of users of both domestic and community-scale biogas ${ }^{2}$ allows for an exploratory consideration of challenges and opportunities associated with individual and collective agency, respectively.

Data collection for the qualitative phase was carried out in the spring of 2014 and consisted of 12 site visits, all involving semi-structured interviews with users of either domestic or community biogas. For the planning of fieldwork, Renewable World ${ }^{3}$ and the Biogas Sector Partnership (BSP-Nepal) ${ }^{4}$ functioned as gatekeepers. The BSP assisted in setting up site visits and providing local contacts to function as guides and translators in the field. Fieldwork was conducted in Kapilvastu, Kaski and Saptari districts (details are provided in Table 4), representing different cultural and geographic contexts, thus reflecting some of the great variety characterising Nepal. Qualitative data collection was carried out based on largely pragmatic sampling, ${ }^{5}$ rather than theoretical/random sampling, due to practicalities in the field.

Visits to community biogas sites involved interviews with representatives of the respective users committees. A users committee is a group of community members responsible for decision-making and arrangements for the operation of a community biogas project. A mix of men and women and castes must be represented (hereby addressing issues of recognition in relation to procedures). Interestingly, in Saptari, the users committee consisted of 31 members, while the minimum requirement, by law, is nine. The president of the committee highlighted this as an effort to make the institution more inclusive. The composition of users committees in the three community sites is detailed in Table 5 .

In Saptari, interviews were carried out with a representative (male) of the users committee. ${ }^{6}$ In Buddhi 1, interviews were carried out with leaders of the users committee (in the company of family members and neighbours); in Buddhi 2, leaders of the users committee were the main interviewees, with the rest of the community all present and engaging with the interview. In Mahuwa, interviews were carried out with the entire community at the insistence of the community members first encountered (most of the men were in the fields, as it was a key period for agriculture, following the first monsoon rain, but were called for by the remaining community members to come and take part in the interview). Interviews with users of domestic biogas digesters depended on who was at home. Eight interviews were completed with both male and female interviewees; 
a BSP registered biogas plants per household (\%) in VDCs
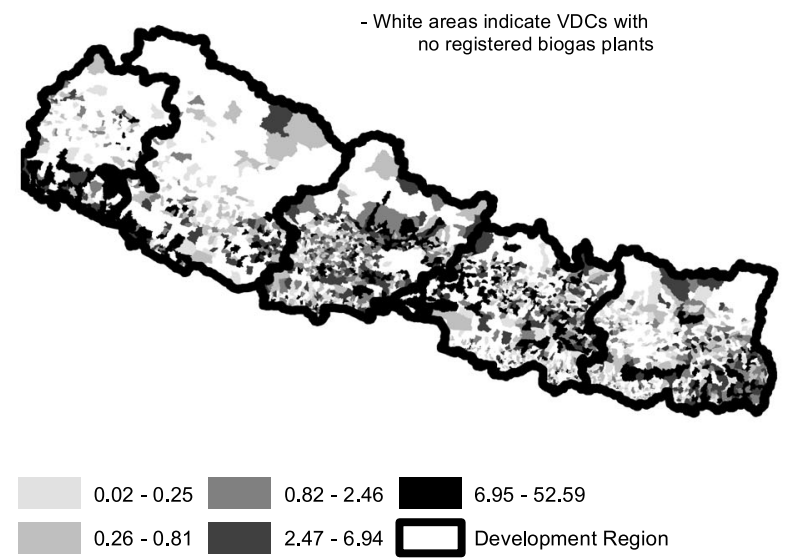

C Distance $(\mathrm{km})$ : VDC centroid through road network to District $\mathrm{HQ}$

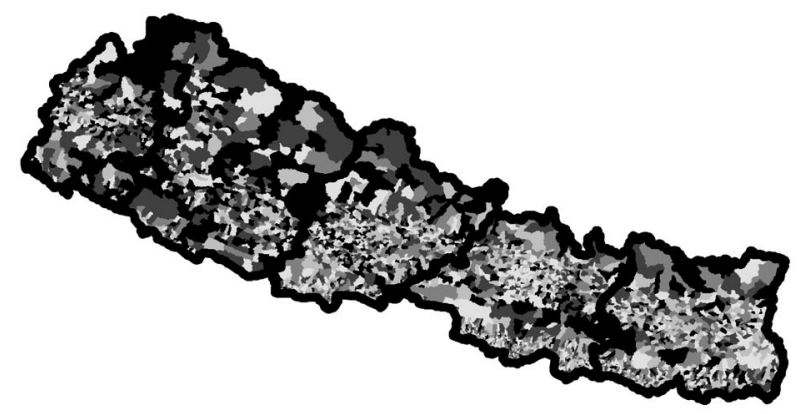

\begin{tabular}{l|l|l}
\hline $0.00-12.22$ & $20.67-29.06$ \\
$12.23-20.66$ & $29.07-42.10$ \\
\hline Development Region
\end{tabular}

e \% of VDC populations categorised as 'marginalised'
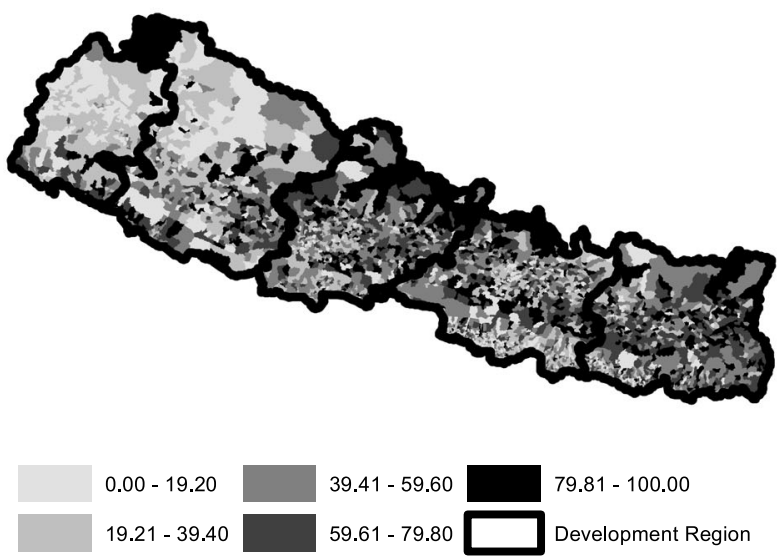

$\bigwedge^{N} \underset{1}{1}, 100,200 \mathrm{~km}$

Fig. 1 Analysed variables (a-f) b Elevation (m)

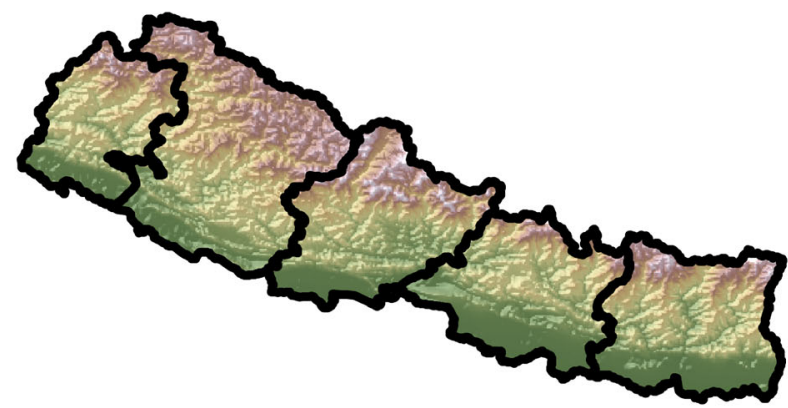

High: 8563

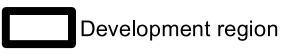

Low: 61

d $\%$ of households in VDCs with no household facilities

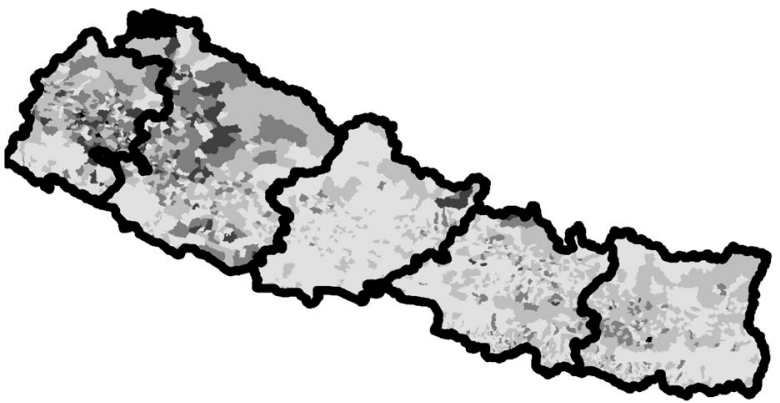

\begin{tabular}{|l|l|l|l|}
\hline $0.00-17.06$ & $34.12-51.17$ & $68.23-85.28$ \\
\hline $17.07-34.11$ & $51.18-68.22$ & Development Region \\
\hline
\end{tabular}

$\%$ of VDC populations made up of women

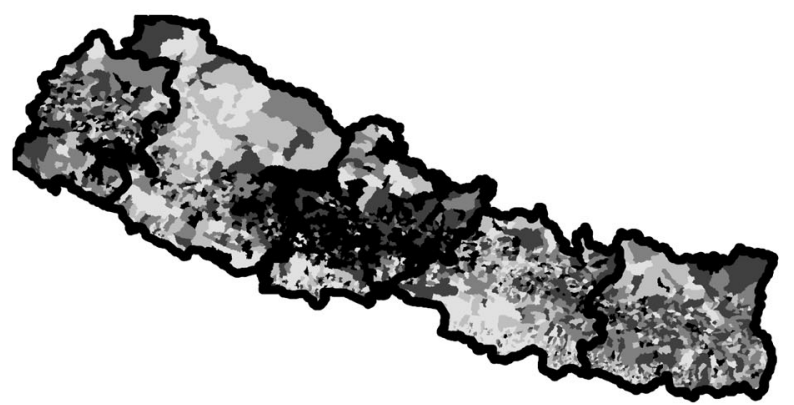

\begin{tabular}{l|l|l|l|}
$0.00-49.82$ & $51.67-53.27$ & \\
$55.00-60.80$
\end{tabular}

$49.83-51.66$ $53.28-54.99$ Development Region 
Table 4 Field sites

\begin{tabular}{ll}
\hline Saptari & An extended visit was made to a community biogas \\
& project, under construction, in Saptari in the southeast, \\
where Renewable World and partner organisations \\
(UNICEF, Chance for Change, SAPPROS, BSP \\
(Biogas Sector Partnership) and CRT \\
(Centre for Rural Technology)) were conducting an \\
Adolescent Development and Participation programme, \\
giving an opportunity to gain insight into not only the \\
construction process but also the community mobilisation \\
schemes surrounding biogas development. \\
Kapilvastu \\
In Kapilvastu, in the south(west), four functioning \\
community plants were visited, located in three different \\
villages \\
(Buddhi 1, Buddhi 2 and Mahuwa). \\
Eight domestic biogas plants were visited in Kaski, in \\
communities surrounding the town of Pokhara.
\end{tabular}

some interviews were conducted with the head of the household, some with a relative of the head of the household. Domestic digesters visited ranged from less than 1 to 28 years old.

The qualitative analysis phase is based on qualitative description as advanced by Sandelowski [35]. We strive to produce a qualitative description of biogas in the everyday terms of biogas-use, in its grounded, realworld context. Participant responses/statements are presented as translated by the translator in the interview, where translation was done using first person and third person interchangeably. Interviews are analysed based on coding performed with a particular emphasis on the post-distributional aspect of energy justice. We present the qualitative data in the 'Qualitative phase' section below with interviewee names and their own words, remaining true to the subjectivity and personality of the research participants.

\section{Results}

\section{Quantitative phase}

Statistical analysis

$\%$ biogas is significantly positively correlated with all selected variables with $\alpha=.05$ (Table 6). The highest observed correlation coefficient $(r)$ was with \% no facilities. Elevation is also correlated highly with both distance and \% no facilities (Table 6), likely relating to accessibility/connectedness, as high-altitude regions in Nepal are very remote with limited infrastructure development.
Conversely, perhaps counter intuitively, the variables representing socially marginalised populations (female and marginalised castes) appear to be negatively correlated with \% no facilities (Table 6).

An ordinary least squares regression model does not explain the dataset well $\left(R^{2} \sim\right.$.087). Residuals from the OLS regression are spatially autocorrelated (Moran's $I=.0946$, $z$-score $=34.1730, p<.01$ ), suggesting that observed spatial patterns may be significant, thus warranting a spatially explicit modelling approach using GWR.

\section{Geographically weighted regression analysis}

All tested GWR models produced randomly distributed residuals, demonstrating an improvement over the OLS results. The optimal model, chosen via the corrected AICc and adjusted $R^{2}$ included four explanatory variables: elevation, distance, \% margin and \% no facilities. The optimal number of neighbours was found to be $k=$ 135 , which is suitable given a study area comprising $n=$ 4050 spatial units. The optimal model accounts for $38 \%$ of variance in the data (with an adjusted $R^{2}=.29$ ). The relatively low adjusted $R^{2}$ suggests that there still may be other factors, not included here, useful for explaining the spatial variation in biogas uptake.

Consistent with technological requirements, elevation has a generally negative effect on the model, with most of the country characterised by local elevation coefficients $<0$ (Fig. 2). Areas assigned a positive elevation coefficient are in the low-altitude Terai region, where the impact on the model will be low (low elevation values multiplied by very small (positive) coefficients), whereas the high altitude, mountainous regions, where elevation values are very high (and thus even with small coefficients will have an impact on the model), all are associated with negative coefficients, as would be expected given temperature dependency of the technology.

Similarly, the coefficients for the variable for household facility ownership feature nationally consistent trends, with almost all locations assigned negative coefficients (higher rates of households with no facilities correlating with lower results for rates of biogas plants) (Fig. 2). Statistically significant values of $\%$ no facilities coefficients are all negative and occur from west to east (Fig. 2). These areas appear to coincide with areas of high biogas penetration (Fig. 1a), suggesting that high

Table 5 User committee composition

\begin{tabular}{llll}
\hline & $\begin{array}{l}\text { Connected } \\
\text { households }\end{array}$ & $\begin{array}{l}\text { Committee } \\
\text { members }\end{array}$ & $\begin{array}{l}\text { Committee: } \\
\text { female/male }\end{array}$ \\
\hline Saptari & 9 & 31 & $\begin{array}{l}\text { Both f and m } \\
\text { castes represented }\end{array}$ \\
Buddhi 1 & 7 & 16 & $6 / 10$ \\
Buddhi 2 & 12 & 12 & $7 / 5$ \\
Mahuwa & $11+6$ & 20 & $9 / 11$ \\
\hline
\end{tabular}


Table 6 Correlations matrix (Pearson's r)

\begin{tabular}{|c|c|c|c|c|c|c|}
\hline & $\%$ biogas & Distance & Elevation & $\%$ female & $\%$ margin & $\%$ no facility \\
\hline$\%$ biogas & & $.040^{*}$ & $-.106^{* *}$ & $.145^{* *}$ & $.109^{* *}$ & $-.252^{* *}$ \\
\hline Distance & $.040^{*}$ & & $.250^{* *}$ & $.079 * *$ & $.154^{* *}$ & $.264^{* *}$ \\
\hline Elevation & $-.106^{* *}$ & $.250^{* *}$ & & $.115^{* *}$ & $.095^{* *}$ & $.303^{* *}$ \\
\hline$\%$ female & $.145^{* *}$ & $.079^{* *}$ & $.115^{* *}$ & & $.169 * *$ & $-.053^{* *}$ \\
\hline$\%$ margin & $.109^{* *}$ & $.154^{* *}$ & $.095^{* *}$ & $.169^{* *}$ & & $-.042^{* *}$ \\
\hline$\%$ no facility & $-.252^{* *}$ & $.264^{* *}$ & $.303^{* *}$ & $-.053^{* *}$ & $-.042^{* *}$ & \\
\hline
\end{tabular}

${ }^{*}$ Correlation is significant at the .05 level (two-tailed); ${ }^{* *}$ correlation is significant at the .01 level (two-tailed)

biogas penetration can be significantly accounted for by high social connectedness (i.e. low rates of \% no facilities). Distance and \% margin both present substantial spatial variation in model coefficients. The map of statistically significant distance coefficients indicates few pockets of significance in the GWR model. Surprisingly, these pockets suggest a positive and significant relationship between distance and \% biogas, which is contrary to what would be expected. This may have to do with the nature of the variable employed. Accounting only for

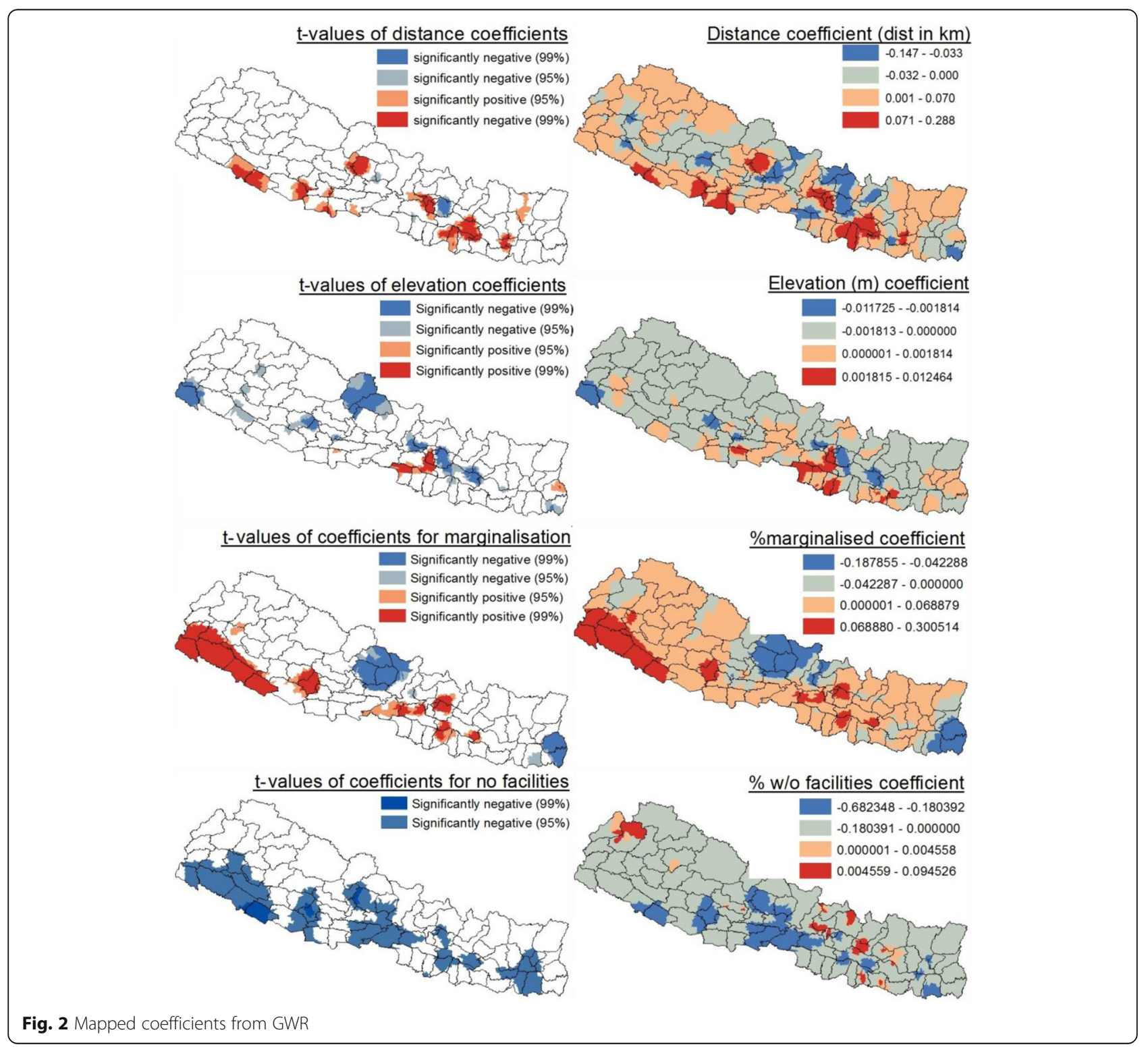


distance does not necessarily capture true accessibility, which depends also on the type of road; the above analysis does not take into account differences between small tracks and large tarmacked roads.

The spatial variation of the coefficient for marginalised castes is particularly interesting. The local coefficients for $\%$ margin clearly cluster with high positive-generally statistically significant (Fig. 2)-impact on biogas in the southwest, but strong negative relationship in the northern part of the Western Development Region and in the far southeast. Dark red and blue areas (i.e. both negative and positive relationships) coincide with areas with high rates of marginalised population. This suggests that high rates of marginalised populations may place some areas at a disadvantage relative to average national biogas development, but not consistently. The positive relationship in the southeast may suggest that subsidy policy aimed at supporting marginalised people has had a significant positive effect in this area. However, to be able to draw such a conclusion firmly, and to explain the geographical variation, further research is needed.

\section{Qualitative phase}

In addition to society-wide distributive processes, energy justice has an important micro-scale aspect relating to the lived experiences of people. This section thus provides a qualitative analysis of interviews with users of domestic and community-scale biogas. Questions guiding the qualitative analysis concern procedures relating to the local development of biogas, with a focus on structures, agency and power dynamics.

\section{Enabling agents: companies and communities}

Biogas companies have an important role in local biogas development. An established culture of biogas-use and common awareness of a local biogas company as the point of contact for biogas-interested households appears to underpin the high penetration of domestic biogas in visited communities in Kaski. As one interviewee states:

Bibek (m) (via translator): Everyone [in the village] is aware of the biogas, everyone has seen it. When anyone thinks that they want a biogas plant, they go directly to the companies...(e)arlier, $10-15$ years earlier, there was a campaign program....and in the campaign program, they [i.e. local biogas companies] collected all the users [i.e. villagers/potential users], and they told about the biogas plant, its benefits, and so on... From that time everyone had heard about the company and everything.

Bibek (m) himself had taken the initiative to contact a biogas company, about 15 years earlier, after neighbours building biogas digesters had awoken his interest. In the same way, Ajita (f) acted on inspiration from neighbours by contacting a biogas company about building a digester herself. Ankur (m), a new settler in his community, had encountered biogas in the village he came from and had decided to construct it in his new home. Ashank (m) serves as an example of ripple effects of a company's penetration into a community. As the first one in his community to construct a domestic biogas digester (at the initiative of a construction company), he actively encouraged his neighbours to consider biogas: 'they got the impression from him' resulting in 95\% of households constructing own biogas digesters (Ashank (m), Interview). These examples highlight the role of neighbourhood inspiration, in addition to the importance of companies' presence in/connection with communities.

In addition to general campaigns, interviewees indicated door-to-door promotions as an effective strategy of the companies, with five out of eight domestic respondents (in Kaski) having been approached by a biogas company, encouraging them to consider building a digester. In this way, companies have reached out to individuals, who may have been aware of biogas in the community, but never considered it a possibility themselves, as in the case of Madhuri (f) and Ashank (m), from different communities in Kaski:

Madhuri (f) (via translator): She had known about the biogas plants, she had seen [them] in the village. But she was not thinking of preparing it [herself].

Ashank (m) (via translator): [...] for the toilet purpose, they constructed the biogas plant. They had heard about the biogas, they had seen in the village, but they were not more aware [about the details]. The company gave the detailed information. (T)hey were thinking about constructing the toilet, and the company came and said that, ok, if you want to construct the toilet, [you should consider] the biogas as well.

Ashank's (m) story is evidence of an integrative strategy behind local biogas development. Biogas is not promoted and developed in isolation and for the sake of the biogas alone, but as part of an interconnected reality, where solutions and technologies can supplement each other and respond to various-very real, concrete and contextual-needs. Such an approach to biogas, as part of holistic solutions for communities or households, is evident to an even greater extent in, for example, the Saptari community project.

The comprehensive holistic approach to energy as part of general community development, seen in Saptari, depends on the types of actors implicated in a community biogas project. Different institutions are involved in community biogas development, where VDCs and 
organisations have approached communities ${ }^{7}$ as initiators of projects. In Buddhi (Kapilbastu), the VDC and a local biogas company approached a community about the building of a community biogas digester. In Mahuwa (Kapilbastu), two community digesters were constructed at the initiative of the Livelihoods and Forestry Programme (LFP), and the project in the visited village in Saptari had been developed collaboratively by UNICEF and Renewable World, with a range of other partner organisations involved in various aspects of a holistic community project. Thus, through their central role in encouraging the uptake of biogas, local companies as well as NGOs and local authorities can be seen as key enabling agents for domestic and community-scale biogas development, respectively.

\section{Supporting structures: public and private funding}

'Enabling agents' operate within a framework of supporting structures, which ensure financial accessibility to the technology, including public subsidies and micro-lending institutions. When asked how digesters were funded, every domestic participant mentioned first the government subsidy (ranging from NPR 8500 to NPR 30,000) and, when asked to elaborate, referred to either 'cash' or 'loan' covering the remaining costs. One participant indicated that it is difficult to repay such a loan, but added that, being 'in service' (working in an office), he is able to manage.

In the case of community biogas construction, the involved organisation(s) appear to be the perceived funding structures (although government subsidy applies here as well but is probably applied for and managed by the organisation). In Mahuwa, for example, the LFP was stated, by participants, as the sole funding body and, in Buddhi, the VDC. The additional required portion of self-funding is, in the community context, often associated with the provision of labour force and materials rather than monetary contribution, as was the case for all visited community biogas digesters. In Saptari, the president $(\mathrm{m})$ of the users committee emphasised that the large community contribution 'put a lot of pressure on the community [financially and timewise, ed.]'.

This aspect of local energy development, as not only involving positive outcomes but also exerting pressure on individuals and communities, is important to consider-especially in situations, where authoritative organisations are the primary initiators, approaching less powerful communities. Here, it is noteworthy that our research finds a clear distinction between the community and domestic biogas contexts, with all community digesters initiated by external NGOs and/or local government, while domestic digesters were constructed on the initiative of the users themselves or in cooperation between the user and a local biogas company. While the direct interaction between enabling (or, in alternative terms: powerful) agents and endusers in Nepal's biogas context raises questions about power relations, our findings suggest that this direct interaction offers opportunities for empowerment, as discussed in the next section.

\section{Empowerment and the end-user}

The centrality of 'enabling agents' in local biogas development in Nepal, in intimate dialogue with end-users, suggests a procedural aspect in small-scale energy development radically different from the 'technocratic authoritarianism' inherent to conventional energy systems [10]. We find that there is, in the small-scale decentralised system, a (potential for) control and participation at the level of the individual, intuitively suggesting greater procedural justice. Plans and arrangements are mutually agreed upon between the company and the user (Madhuri (f) interview; Ajita (f) interview) and can be tailored to individual needs and abilities (Ashank $(\mathrm{m})$ interview). Empowerment lies also in the day-to-day production and consumption processes, where individual user training equips users to control operation of their biogas digester.

While domestic participants were unanimously satisfied with the training received, community participants were more prone to criticising the limited extent of training, in line with a general tendency, amongst community participants, to express more normative and critical views. Generally, normative statements suggested an expectation around individual responsibility, either directly, as expressed by a community member in Buddhi:

Male (via translator): This is our property ... and all the households should take responsibilities.

or through a desire for more extensive training, as expressed by community members in Mahuwa:

Male (via translator): We are not trained; we are only trained how to operate, so whenever we need, we have to call for help.

Female (via translator): I know how to open and close the valve.

Researcher: Do you find that a problem, or is that ok?

Male (via translator): It's not a good thing that we don't know how to handle all the things, because if we 
knew about that, we wouldn't have to wait for the company ... We could manage ourselves. And it would be [a] safer, easier and faster way.

Thus, our findings suggest that biogas users in Nepal embrace increased agency and associated responsibility with an appetite for greater empowerment, valuing decision freedoms on the matter of energy. This is significant in light of Sen's [13] emphasis on the need for a balance between freedom to make decisions and freedom from having to make trivial decisions, which relates to Adams' and Bell's [4] concept of "perceived convenience" of current energy structures. In the name of alternative energy solutions, our findings point to the potential in perceiving of energy decisions not as trivial and inaccessible, as nuances or burdens, but rather emphasise the potentials in such decision freedoms $[4,36]$.

\section{Power dynamics}

As discussed above, in the domestic biogas context, the procedures involved in acquiring, producing and consuming energy have to do with decisions surrounding acquisition, planning and funding of the plant and subsequently concern user training and plant maintenance. These procedures involve the user and biogas construction company as key actors, within an overarching framework of national biogas associations and funding bodies (including a government subsidy scheme and micro-finance institutions). From the perspective of procedural justice, the concern here would be with a 'vertical' procedural justice (Fig. 3), focusing on the extent of user participation and agency, and 'vertical' power relations within this framework.

While critical analysis of the power exercised by biogas companies and other 'enabling agents' over households and communities remains essential, our research suggests that vertical power dynamics in small-scale energy development are (potentially) more balanced and inclusive than those characteristic of large-scale, centralised energy contexts. There are important differences between the 'powerful' agents in the two contexts: large, external energy providers, remotely owned and managed, as opposed to smaller, locally based and locally owned companies. Furthermore, there is a clear distinction between the typical energy provider in the centralised energy system, providing electricity as a good, in contrast to the provision, in the context studied here, of micro-generation technologies, providing customers with the capacity to provide for themselves.

Based on our findings, a 'vertical' conceptualisation of procedural justice applies also in the community biogas context, albeit with different actors involved (NGOs, local authorities), in addition to what may be termed a 'horizontal' dimension (Fig. 3). In this context, construction, organisation and day-to-day operation involve cooperation and processes of direct democracy through the institution of the users committee, an institution with the potential to address both procedural and recognition aspects of energy justice.

Our findings show how the horizontal dimension presents both a challenge and a potential for community mobilisation. On the one hand, participants from the community biogas context highlighted difficulties in managing the shared responsibility for feeding and operating the plant, as exemplified in below excerpt from a community participant in Buddhi:

Male (via translator): They all know how to operate the plant, and his wish is that all the family members, the families that are using, should contribute equal water, equal dung, ... [But] some 1 or 2 members are neglecting the rules...

On the other hand, involvement in continuous decisionmaking and cooperation processes appeared to inspire critical thinking and potentially broader engagement with

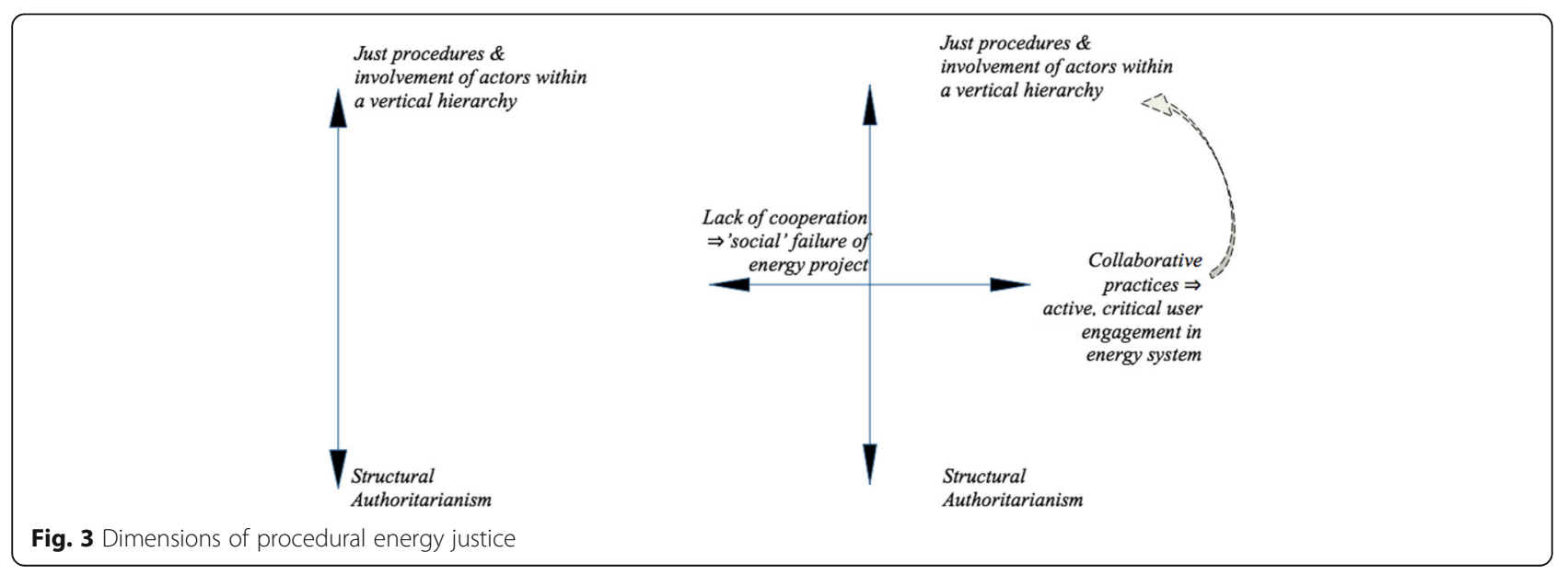


the system by community participants. There was a striking difference between the way in which participants, from domestic and community contexts, respectively, deliberated over the processes involved in biogas attainment and operation. Community participants offered more critical and normative perspectives on biogas-related processes/ matters (from community dynamics to matters of training and maintenance and relations with construction companies and authorities) than participants from the domestic biogas context.

Hence, while a notion of 'horizontal procedures' may present users and developers of energy projects with new challenges, pressures and responsibilities, these may also have greater transformative potential, if appropriately managed, than procedures in purely vertically organised energy systems. Although the vertical dimension can certainly embrace ideas of justice, such vertical justice is unlikely to challenge established institutions or social orders ${ }^{8}$; instead, the horizontal dimension, in its potential enhancement of critical user engagement, may be where innovative democratic developments can occur-if appropriate practices are facilitated and supported as part of the energy project.

\section{Instrumental and procedural gender benefits}

Our exploratory research also indicates that these different dimensions of procedural energy justice between domestic and community biogas development have implications for the linking of gender equality objectives with the promotion of small-scale biogas in Nepal. The primary connection made between biogas and gender is the important health benefits of improving indoor air quality and the reduced time and effort spent collecting traditional sources of fuel (the 'Case selection: Nepal and biogas' section). These are direct, instrumental benefits, overwhelmingly benefiting women due to typical gender roles in the household. Meanwhile, similar to the above discussion of 'horizontal' procedural justice in the community biogas context, it is possible to conceive of a more fundamental, procedural shift in societal gender dynamics in the context of community biogas, through the compulsory participation of women in users committees. However, while women were well represented in users committees in all visited communities (Table 5, the 'Qualitative phase' section ), it was evident, from an interview in Buddhi 2, that this level of inclusion remains unusual and contrasts the general norm: "they said females are more in the posts, so they are laughing!" Similarly, while community interviews tended to be with several (if not all) members of the community, a man always acted as main spokesperson, and even if initial contact was made with a woman, she would insist that the interview be conducted once the man/men were called for to participate.
Previous studies have highlighted the challenges of breaking traditional gender norms in relation to participation in community projects (such as forestry or energy projects) in Nepal and elsewhere [37, 38]. Thus, for projects such as community biogas to have social transformative potential, and encourage changed gender dynamics through increased participation by women in the community, this must be actively facilitated and supported as an underlying aim of the project (see also [24, 39]).

While the participation of women was an explicit part of community biogas on the ground, concerns about caste and ethnic equality did not appear to be an explicit concern amongst the communities visited. Decisions about household connection to the community biogas digester were entirely pragmatic, based on proximity to the digester and willingness and ability to participate, and these issues were not discussed in relation to castes. Inclusion in the users committee, in turn, was based on participation in the biogas project and requirements relating to gender equality; caste did not appear to be an explicit issue. Relating this to the findings from our quantitative analysis, the caste aspect of recognition justice in Nepal appears to operate at larger scale, associated more with larger areas of high levels of marginalised populations (i.e. inter-community or inter-regional processes), rather than at the inter-household level within communities. On the contrary, processes of gender recognition did not appear significant in our quantitative analysis, suggesting that caste and gender aspects of recognition justice operate at different spatial scales (section 3.1.3), as VDC-level spatial analysis appeared useful for the caste variable, but less so for the gender variable.

\section{Discussion}

\section{Achieving energy justice in unconventional energy systems}

The emerging concept of energy justice emphasises the multi-scalar and multi-dimensional nature of energy systems, the vast difference between energy realities in different parts of the world, and acknowledges the need for context specificity [2]. Yet, it is a concept originating in 'western' energy studies, rooted in concerns over centralised, conventional energy systems and negative externalities/burdens, and a concept building on predominantly 'western' discourses of (human) rights. In the following, energy justice is critically discussed, based on our research findings, in relation to unconventional energy development.

Energy scholarship on non-western contexts and unconventional energy systems has tended to focus on equality rather than justice [15], with greater emphasis on poverty alleviation and equal development than on the burden/benefit dilemma, which is central to the 
energy justice concept. Energy (and environmental) justice tend to be perceived in relation to large-scale processes, systems and structures, whereas development and poverty alleviation-dominant arenas for unconventional energy solutions-are typically associated with discourses more concerned with individuals and, above all, equality between individuals. A degree of disconnect is common in energy scholarship, between work at the level of the individual, of the community and of society, a division beginning to be questioned and problematized [40]. Learning from the kinds of issues, traditionally located in the domain of unconventional, non-Western energy contexts and international development scholarship-as we have attempted here-might allow energy justice research to bridge this and divide and consider not only the large-scale processes of justice but also the simultaneous lived experiences of justice from the perspective of individuals and communities. Such development within energy justice scholarship will make it better suited to the study of non-Western energy contexts and decentralisation as part of a low-carbon energy transition.

There is a two-way learning potential, with energy justice also offering useful insights for the study and practice of energy development otherwise dominated by a focus on equality and poverty alleviation. Energy justice goes beyond the notion of equal access to energy, to incorporate such issues as common goods, individual capability and power. An energy justice perspective links fair and equal energy access to wider challenges around common goods, whether at the global scale, involving environment, climate and common pool resources or-as more characteristic of small-scale systems such as in Nepal-local, immediate environments, where such issues as deforestation and indoor air quality are intimately linked to processes of energy production and consumption. Energy justice also encourages attention beyond gender equality or ethnic equality, emphasising ideas more directly related to capability and functioning. For example, spatial analysis of distributions, as applied in this paper, can investigate who, in society, may be more or less capable of attaining, for example, biogas and, by extension, who might need to be targeted/supported, and where, to facilitate capability and functioning in fair ways.

This is not to suggest that a focus on energy equality ignores underlying processes of social equality or justice, as is evident, for example, in the literature and policy initiatives that seek to empower women and disadvantaged social groups through targeted energy development and social mobilisation (e.g. [39, 41, 42]). However, where a study of equality may assess whether disadvantaged groups are sufficiently reached, it is through principles of justice such as Rawls' difference principle and
Sen's emphasis on differential abilities to convert resources into functionings and agency (see the 'Energy justice and the capability approach' section) that energy development can be assessed in relation to its creation of real, experienced empowerment. Above all, energy justice offers a framework for thinking about procedures, agency and power.

While small-scale, decentralised energy development appears intuitively more just than the 'authoritarian technics' of large-scale, centralised energy development, the analysis of power dynamics is equally important to ensure just procedures in small-scale development. Our findings highlight both the empowering potential of small-scale energy solutions and the unique dynamics of power which must be recognised. Interestingly, we found dynamics of power and agency to differ across the domestic and community energy contexts. While we found the domestic context to be characterised by a higher level of individual agency than the community context, where biogas projects were primarily externally initiated, the latter appeared to offer a deeper transformative potential through processes of direct democracy within the community. This added 'horizontal dimension' of power presents an important challenge to be addressed in community energy projects.

\section{The challenges of user agency in unconventional energy systems}

Both qualitative and quantitative findings highlight the importance of user agency, as seen locally in stories of individual initiative and discourses of individual responsibility in biogas attainment and operation. With this in mind, the association revealed in the quantitative analysis between low biogas penetration and lack of access to household facilities gains significance. Lack of connectedness (or lack of financial resources) can be translated into a barrier to agency, following Sen's [12] concepts of functioning and agency deprivation. From this perspective, energy justice in small-scale unconventional contexts becomes about creating individual agency capability, through enabling and supporting frameworks, institutions, practices and cultures.

Central to this enabling framework is subsidies. Our study finds that they offer much needed support to marginalised populations. This was particularly the case in the southeast. While not conclusive, subsidies can be an important mechanism for aiding community and household biodigester roll out. In this way, we remind literature on energy justice that subsidies are not always a negative tool as claimed by some scholars [3]. Within this context, we find that companies can play a significant role in this enabling framework through knowledge transfer, aided by neighbourhood inspiration after positive experiences are shared. 
The focus of energy justice scholarship on centralised, conventional energy systems and associated benefit/burden geographies inspires a discourse revolving around rights of the individual, and responsibilities of the system, and a central concern with violations against communities. While these are critical concerns, in any system of any kind, conventional or unconventional, large-scale or small-scale or centralised or decentralised, we suggest that a more nuanced discourse is necessary around energy justice. Strikingly, participants in this research project spoke almost entirely about the necessity of personal responsibility when making normative statements about their perception of local biogas development. Thus, for the energy justice concept to apply to, or even encourage, unconventional energy solutions, the connection needs to be emphasised-not as divided amongst different actors but as existing together-of rights, responsibility and agency.

A similar argument about individual and community responsibility has been made with reference to a postdistributive notion of climate justice [43, 44]. The increasing connection between the user and provider makes this challenge even greater when we look at the growing similarity of energy systems. Parag and Sovacool [45] reveal that small-scale intimate user-provider energy systems are progressively usurping conventional largescale systems in the 'developed' world. They observe a similar trend from end-user to 'prosumer'. The challenge of successfully connecting rights, responsibility and agency are therefore not limited to developing world contexts.

\section{Conclusions}

To advance the emerging concept of energy justice in the context of unconventional energy development, small-scale bioenergy development in Nepal was studied by way of two research questions, associated with a quantitative and qualitative research phase: (1) how does the geographical distribution of small-scale bioenergy plants relate to the physical and social landscapes of Nepal? and (2) how does bioenergy development/practice "on the ground" address post-distributive aspects of justice in Nepal?

Our quantitative analysis showed how energy justice may be applied to study national processes of decentralised energy development, to investigate processes of distributive justice, while qualitative enquiry provided a micro-scale investigation into the 'post-distributive' issues of procedures, agency and empowerment, to define energy justice in relation to small-scale unconventional energy realities. Based on this study, it is suggested that research into processes of responsibility and agency capability in different energy systems and at different scales could further advance the concept of energy justice, to better apply to, and even encourage unconventional, small-scale energy solutions.
In order to address energy justice in the context of unconventional energy development and in relation to novel structures, power dynamics and agents in the energy system, we need to emphasise the coexisting principles of rights, responsibilities and agency-not as divided amongst different actors or institutions but as operating at all levels of an energy system and applying to all actors.

\section{Endnotes}

${ }^{1}$ The term post-distributive justice is here associated with procedural and recognition aspects of energy justice and their 'articulation in particular places' [43, 44]. Working on climate justice, Bulkeley et al. [44] employ the postdistributive concept 'to engage with how climate justice is actually practised and embedded in the city'.

${ }^{2}$ Participants involved in community biogas projects will be referred to as community participants, and participants living with a domestic (household) biogas digester will be referred to as domestic participants.

${ }^{3}$ Renewable World is an international NGO working on rural electrification projects in Nepal, amongst other places, and is particularly involved in community-scale energy projects, including community biogas development.

${ }^{4}$ BSP-Nepal has the status of an NGO and is the implementing body for the Biogas Support Program, a programme coordinated in partnership with the government's Alternative Energy Promotion Center (the project sponsor).

${ }^{5}$ Sampling was done in cooperation with field guides (generally, representatives from local biogas companies) independently of Renewable World and the BSP, who were, however, involved in general site selection. Potential sampling bias must thus be kept in mind in relation to these organisations as well as local companies.

${ }^{6}$ In the context of community biogas projects, a 'users committee' is set up to manage the operation of the project. This committee must be made up of both male and female representatives.

${ }^{7}$ Respective organisations typically select a community based on predefined (socio-economic) criteria and initial feasibility studies.

${ }^{8}$ It is, however, worth considering, as previously discussed, a transformative potential within the vertical dimension if dealing with decentralised, locally integrated energy development vis a vis large-scale, commercial energy development.

\section{Acknowledgements}

The authors would like to thank Renewable World and the BSP for their cooperation. Special thanks to Mr. Keshav Khanal and colleague of Janapriya GobargasTatha Nirman Company and their families and Pusparaj Koirala of the NBPA for their assistance in the field. 


\section{Authors' contributions}

CSD conceptualised the research and was solely responsible for the data collection and analysis. DM and $J \mathrm{~L}$ supervised the project, contributed to the critical reading of the manuscript and provided input to the final version. All authors read and approved the final manuscript.

\section{Authors' information}

Caroline Sejer Damgaard is a PhD researcher in the Department of Geography and Sustainable Development. Her current research focuses on social preferences relating to organisational structures in urban energy transitions.

Dr Darren McCauley is a Senior Lecturer in the Department of Geography and Sustainable Development. He is a Director of the Arctic Research Centre which is a St. Andrews and Moscow State collaborative endeavour. He holds a number of external positions including Visiting Professor at the International Hellenic University. His research interests include energy policy analysis, assessing and promoting equity and fairness in energy systems and developing interdisciplinary approaches to energy problems.

Dr Jed Long is a lecturer in the Department of Geography and Sustainable Development, University of St Andrews. His research interests include spatial modelling, geographic information systems and computational geography.

\section{Competing interests}

The authors declare that they have no competing interests.

\section{Received: 23 August 2016 Accepted: 28 February 2017} Published online: 27 March 2017

\section{References}

1. OECD/IEA (2013) World Energy Outlook - Executive Summary

2. Goldthau A, Sovacool BK (2012) The uniqueness of the energy security, justice, and governance problem. Energy Policy 41:232-240. doi:10.1016/j. enpol.2011.10.042

3. Sovacool BK, Heffron RJ, McCauley D et al (2016) Energy decisions reframed as justice and ethical concerns. Nat Energy 1:16024. doi:10.1038/nenergy. 2016.24

4. Adams CA, Bell S (2014) Local energy generation projects: assessing equity and risks. Local Environ 1-16. doi: 10.1080/13549839.2014. 909797

5. McCauley D, Heffron RJ, Stephan H, Jenkins K (2013) Advancing energy justice: the triumvirate of tenets. Int Energy Law Rev 32:107-110

6. McCauley D, Heffron R, Pavlenko M et al (2016) Energy justice in the Arctic: implications for energy infrastructural development in the Arctic. Energy Res Soc Sci 16:141-146. doi:10.1016/j.erss.2016.03.019

7. Schlosberg D (2003) The justice of environmental justice: reconciling equity, recognition and participation in a political movement. In: Light A, De-Shalit A (eds) Moral Polit. Reason. Environ. Pract. New York: MIT Press. p. 77-106

8. Bickerstaff K, Walker GP, Bulkeley H (2013) Introduction: making sense of energy justice. Energy Justice in a Changing Climate. London: Zed Books; p. 5-21

9. Jenkins K, McCauley D, Heffron R, et al (2006) Energy justice: a conceptual review. Energy Res \&amp; Soc Sci 11:174-182

10. Sovacool BK, Sidortsov RV, Jones BR. (2014) Energy security, equality, and justice. New York: Routledge

11. Sen A (1979) Equality of what? Tann. Lect. Hum. Values

12. Sen A (1992) Inequality reexamined. New York: Oxford University Press

13. Sen A (1999) Development as freedom. New York: Oxford University Press

14. European Environmental Bureau (2011) Saving energy in Europe: 15 good practice case studies

15. Cherp A, Jewell J, Goldthau A (2011) Governing global energy: systems, transitions, complexity. Glob Policy 2:75-88. doi:10.1111/j.1758-5899.2010. 00059.x

16. Hall SM (2013) Energy justice and ethical consumption: comparison, synthesis and lesson drawing. Local Environ 18:422-437. doi:10.1080/ 13549839.2012.748730

17. Walker G (2009) Beyond distribution and proximity: exploring the multiple spatialities of environmental justice. Antipode 41:614-636. doi:10.1111/j. 1467-8330.2009.00691.x

18. Mumford L (1964) Authoritarian and democratic technics. Technol Cult 5:1-8
19. Walker G, Day R (2016) Necessary energy uses and a minimum standard of living in the United Kingdom: energy justice or escalating expectations? Energy Res Soc Sci 18:129-138. doi:10.1016/j.erss.2016.02.007

20. Miller CA, lles A, Jones CF (2013) The social dimensions of energy transitions. Sci Cult (Lond) 22:135-148. doi:10.1080/09505431.2013. 786989

21. Bassam N El, Maegaard P, Schlichting ML (2013) Distributed renewable energies for off-grid communities. New York: Elsevier Inc

22. Sovacool BK, Ryan SE, Stern PC et al (2015) Energy research \& social science integrating social science in energy research. Energy Res Soc Sci 6:95-99. doi:10.1016/j.erss.2014.12.005

23. Gurung A, Gurung OP, Oh SE (2011) The potential of a renewable energy technology for rural electrification in Nepal: a case study from Tangting. Renew Energy 36:3203-3210. doi:10.1016/j.renene. 2011.03.012

24. Sovacool BK, Bambawale MJ, Gippner O, Dhakal S (2011) Electrification in the mountain kingdom: the implications of the Nepal power development project (NPDP). Energy Sustain Dev 15:254-265. doi:10. 1016/j.esd.2011.06.005

25. Mainali B, Silveira S (2011) Financing off-grid rural electrification: country case Nepal. Energy 36:2194-2201. doi:10.1016/j.energy.2010.07.004

26. Surendra KC, Khanal SK, Shrestha P, Lamsal B (2011) Current status of renewable energy in Nepal: opportunities and challenges. Renew Sustain Energy Rev 15:4107-4117. doi:10.1016/j.rser.2011.07.022

27. Gurung A, Oh SE (2013) Conversion of traditional biomass into modern bioenergy systems: a review in context to improve the energy situation in Nepal. Renew Energy 50:206-213. doi:10.1016/j. renene.2012.06.021

28. Sovacool BK, Dhakal S, Gippner O, Bambawale MJ (2011) Halting hydro: a review of the socio-technical barriers to hydroelectric power plants in Nepal. Energy 36:3468-3476. doi:10.1016/j.energy.2011.03.051

29. Bennett L, Dahal DR, Govindasamy P (2008) Caste, ethnic and regional identity in Nepal_further analysis of the 2006 Nepal demographic and health survey

30. Manandhar U, Bhatta G (2013) Biogas for climate justice : a story of change in Nepal. Hunger. Nutr. Clim. Justice

31. Barnhart S (2013) From household decisions to global networks: biogas and the allure of carbon trading in Nepal. Prof Geogr 1-9. doi:10.1080/00330124. 2013.821720

32. Chuanyan Z, Zhongren N, Guodong C (2005) Methods for modelling of temporal and spatial distribution of air temperature at landscape scale in the southern Qilian mountains, China. Ecol Modell 189:209-220. doi:10. 1016/j.ecolmodel.2005.03.016

33. Anselin L, Griffith D (1988) Do spatial effects really matter in regression analysis? Pap Reg Sci Assoc 65:11-34

34. Fotheringham AS, Brunsdon C, Charlton M (2003) Geographically weighted regression: the analysis of spatially varying relationships. Wiley

35. Sandelowski M (2000) Whatever happened to qualitative description? Res Nurs Health 23:334-40

36. Mittlefehldt S, Tedford C (2014) Benefit or burden? Environmental justice and community-scale biomass energy systems in Vermont. Environ Justice 7:110-114. doi:10.1089/env.2014.0019

37. Khadka M, Karki S, Karky BS et al (2014) Gender equality challenges to the REDD+ initiative in Nepal. Mt Res Dev 34:197-207. doi:10.1659/MRDJOURNAL-D-13-00081.1

38. Fernández-Baldor Á, Boni A, Lillo P, Hueso A (2013) Are technological projects reducing social inequalities and improving people's well-being? A capability approach analysis of renewable energy-based electrification projects in Cajamarca, Peru. J Hum Dev Capab 15:13-27. doi:10.1080/ 19452829.2013.837035

39. Gippner O, Dhakal S, Sovacool BK (2012) Microhydro electrification and climate change adaptation in Nepal: socioeconomic lessons from the rural energy development program (REDP). Mitig Adapt Strateg Glob Chang 18 : 407-427. doi:10.1007/s11027-012-9367-5

40. Sarrica M, Brondi S, Cottone P, Mazzara BM (2016) One, no one, one hundred thousand energy transitions in Europe: the quest for a cultural approach. Energy Res Soc Sci 13:1-14. doi:10.1016/j.erss.2015. 12.019

41. Government of Nepal (2009) Subsidy policy for renewable (rural) energy 2009 (2066 BS). Ministry of Environment Alternative Energy Promotion Centre, Kathmandu. 
42. Lama A, Buchy M (2002) Gender, class, caste and participation: the case of community forestry in Nepal. Journal of Gender Studies. 9(1):27-41. Accessed 9 Mar 2014

43. Bulkeley H, Edwards GAS, Fuller S (2014) Contesting climate justice in the city: examining politics and practice in urban climate change experiments. Glob Environ Chang 25:31-40. doi:10.1016/j.gloenvcha.2014.01.009

44. Bulkeley H, Carmin J, Castán Broto V et al (2013) Climate justice and global cities: mapping the emerging discourses. Glob Environ Chang 23:914-925. doi:10.1016/j.gloenvcha.2013.05.010

45. Parag Y, Sovacool BK, Bazilian M et al (2016) Electricity market design for the prosumer era. Nat Energy 1:16032. doi:10.1038/nenergy.2016.32

\section{Submit your manuscript to a SpringerOpen ${ }^{\circ}$ journal and benefit from:}

- Convenient online submission

- Rigorous peer review

- Immediate publication on acceptance

- Open access: articles freely available online

- High visibility within the field

- Retaining the copyright to your article

Submit your next manuscript at $>$ springeropen.com 